\title{
A Technical Brief
}

DOE $/$ CH-10093-251

\section{Brayton-Cycle Solvent Recovery Heat Pump}

November 1994

Office of Industrial Technologies

Assistant Secretary for Energy Efficiency and Renewable Energy

U.S. Department of Energy

Contents

Summary . . . . . . . . . . . . . 2

Introduction ............. 3

Project History and Status . . . . . . . . . . 6

Testing ............... . 8

Applications . . . . . . . . . . 13

For More Information . . . . . . . . . . 19

\section{MASTER}

DISTRIBUTION OF THIS DOCUMENT IS UNLIMITED 


\section{DISCLAIMER}

This report was:prepared as an account of work sponsored by an agency of the United States Government. Neither the United States Government nor any agency thereof, nor any of their employees, make any warranty, express or implied, or assumes any legal liability or responsibility for the accuracy, completeness, or usefulness of any information, apparatus, product, or process disclosed, or represents that its use would not infringe privately owned rights. Reference herein to any specific commercial product, process, or service by trade name, trademark, manufacturer, or otherwise does not necessarily constitute or imply its endorsement, recommendation, or favoring by the United States Government or any agency thereof. The views and opinions of authors expressed herein do not necessarily state or reflect those of the United States Government or any agency thereof. 


\section{DISCLAIMER}

Portions of this document may be illegible in electronic image products. Images are produced from the best available original document. 


\section{Summary}

$T$ he U.S. Department of Energy's (DOE's) Office of Industrial Technologies (OIT) sponsors research and development $(R \& D)$ to improve the energy efficiency of American industry and to provide for fuel flexibility. Working closely with industry, OIT has successfully developed more than 50 new technologies that saved industry approximately 80 trillion Btu (84 quadrillion joules) of energy in 1992. More than 200) other projects are in various stages of development from laboratory research to field tests.

The use of solvents in the industrial ertor is widespread and results in the emission of rolatile organic compounds (VOCs) to the atmemphere. These VOC emissions represent an ecconomic loss to industry and contribute significanth to air pollution. To comply with increasingly strict enu uronmental regulations while keeping come down, industry must find efficient and comt e.ffertise ways to control emissions from solvent ux'

Conventional emission control technolingless used by industry include incineratıon and carbon adsorption with steam regeneration Bu ith pror cesses are energy intensive; incineratun al $(x)$ results in the loss of the solvents and the'r embodied energy. Although carbon adsorptum iteam regeneration systems allow the solvents to be recovered, the capital and operating comt are sometimes prohibitive, especially for small solvent users.

As an alternative to these conventional technologies, OIT has been sponsoring the development of the Brayton-cycle solvent recovery heat pump in cooperation with the 3M Company (3M). Several other industrial participants have also been involved in the project, including AiResearch Manufacturing Company (AiResearch), NUCON International, Inc. (NUCON), Southern California Edison, the Electric Power Research Institute (EPRI), and Dow Chemical Company.

The new technology enables cost-effective solvent recovery through condensation at low temperatures, minimizing solvent emissions .while reducing overall energy consumption. The technology is based on a well-established thermodynamic cycle, the reverse Brayton cycle, that uses the principle of reducing the pressure of air to lower its temperature. The Brayton cycle is flexible, inherently stable, and has the ability to reach very low temperatures in a short time. The technology's reliability has been established through decades of use in air-conditioning systems on commercial and military jet aircraft, and in cryogenic air separation plants.

$R \& D$ efforts on the Brayton-cycle heat pump since the late 1970s have resulted in the operation of large systems at three of 3M's manufacturing facilities. The first system uses a straight condensation process; the second system incorporates carbon adsorption beds with the technology; the third system is an advanced Brayton system. To service small emitters, a pilot-scale mobile unit was tested. This led to the design and fabrication of a small, decoupled heat pump which was tested in southern California.

The Brayton-cycle solvent recovery heat pump offers low energy costs and competitive capital and operation and maintenance (O\&M) costs compared to other conventional recovery technologies. Maximum savings of up to 110 trillion Btu/yr (115 quadrillion joules) (based on the physical quantity of recovered solvents) and up to $\$ 1.5$ billion/yr (based on the solvent value) have been predicted based on the use of the technology to recover eight widely used solvents. Payback periods of less than 3 years are possible for the operating systems; even shorter paybacks are expected for future systems.

This technical brief describes the work performed in the DOE project and highlights the industrial testing of the Brayton systems. Through the publication of this document, OIT seeks to make the results of the project available to other researchers and private industry, especially those interested in commercial uses of this technology. The report discusses the R\&D efforts, project status, and the potential impact that this promising technology will have on industry. 
$\mathrm{O}$ ver 2.7 billion pounds ( 1.2 billion $\mathrm{kg}$ ) of VOCs are lost to the atmosphere annually from industrial processes within the United States. This represents over $90 \%$ of the solvents used in industry. The removal of VOCs or solvents (e.g., methylene chloride, toluene, alcohols, and chlorofluorocarbons) from industrial effluent streams is required for compliance with environmental regulations such as the Clean Air Act. Industry is thus faced with the following options:

- Minimize VOC (solvent) emissions.

- Eliminate the need for solvents in manufacturing processes.

- Control solvents by destruction.

- Control solvents by recovering and recycling them to reusable solvents.

\section{VOC Control Technologies}

Solvent removal without recovery is accomplished by incineration. Both thermal and catalytic incineration are used, depending on the type and concentration of VOCs present. These methods are energy intensive, because supplementary fuel is required to destroy the VOCs. Supplementary energy use can be reduced through the use of regenerative or recuperative incineration, in which a portion of the heat of combustion is recovered.

The recovery of solvents is becoming an attractive alternative to solvent destruction because of the increasing costs of solvents and the possibility for their reuse. Solvent recycling offers the opportunity to save a significant amount of energy, about 50 trillion Btu (53 quadrillion joules) annually, with a value of over $\$ 200$ million. This energy savings reflects the recapture of the embodied energy value of the solvent. The capability of recovering solvents may also encourage industry to use more expensive solvents that are less toxic or more beneficial from the product and process viewpoint.

Conventional solvent recovery techniques include adsorption and condensation using a refrigerative Rankine cycle. In the adsorption process, carbon beds are used to selectively adsorb solvents from a contaminated stream. Steam or inert gas is passed through the beds to remove the solvents (i.e., to regenerate the beds). If steam is used, an energy-intensive distillation step may be required to separate water from the recovered solvents. The use of hot, inert gas for regeneration-such as that provided by a Brayton-cycle system-eliminates the need for the distillation step.

Conventional recovery systems are usually cumbersome and energy intensive. For example, a typical carbon adsorption/steam regeneration process with distillation requires about $10,000 \mathrm{Btu} / \mathrm{lb}$ (23 million joules $/ \mathrm{kg}$ ) of recovered solvent. In addition, carbon beds cannot be used to absorb all types of solvents. The other conventional recovery technique-condensation by refrigeration-is both energy intensive and may take up to 2 hours to reach steady-state operation.

During the last 15 years, technical advancements have allowed the reverse Brayton-cycle process to compete favorably with conventional techniques for the recovery of solvents from industrial effluent streams in many applications. A carbon adsorption/Brayton-cycle regeneration system may be more cost effective and energy efficient than a system using steam regeneration, particularly for solvents that are miscible with water. When used for solvent condensation by refrigeration, the Brayton cycle can achieve lower temperatures with less energy and less equipment. The process is also flexible and can achieve its low operating temperatures very rapidly.

DOE's OIT has been actively involved in the development of the Brayton-cycle solvent recovery heat pump for solvent recycling and reuse since the early 1980s. OIT-sponsored research has resulted in the development and demonstration of Brayton-cycle recovery systems for several industrial solvent applications. 

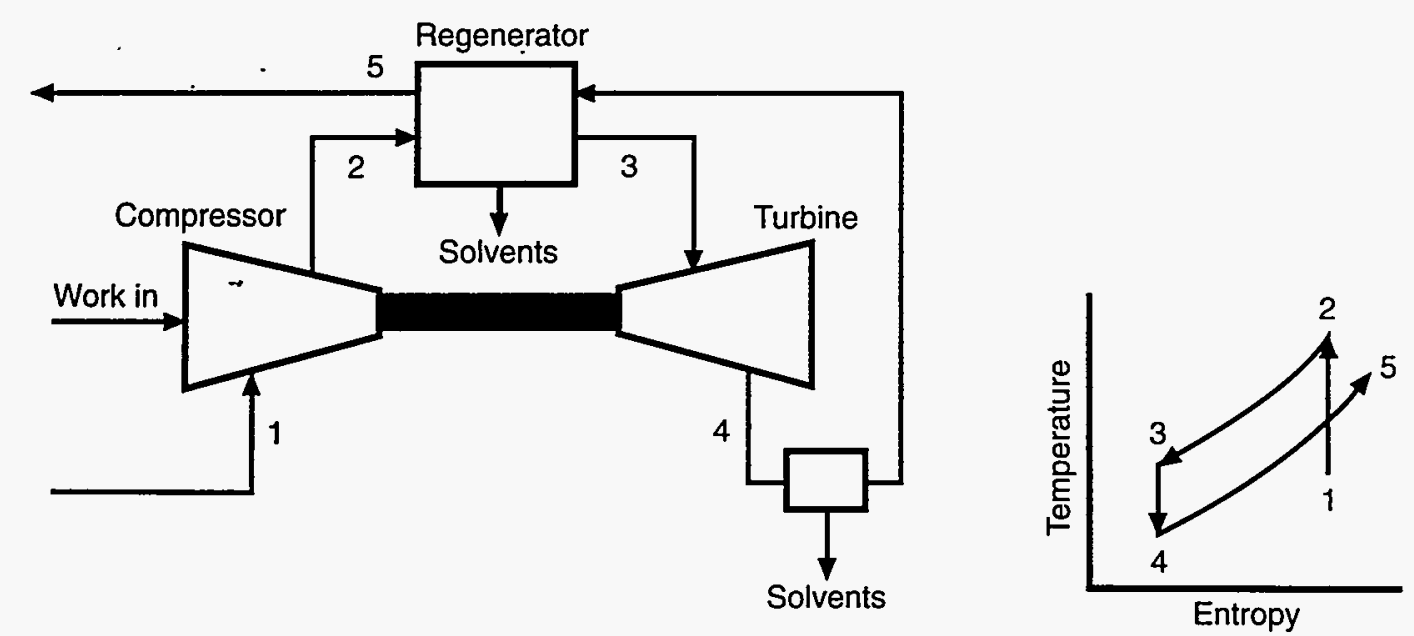

Figure 1. Ideal regenerative reverse Brayton cycle

\section{Description of the Brayton Cycle}

The Brayton cycle is a thermodynamic cycle consisting of two reversible constant pressure processes combined with two constant entropy (isentropic) processes. It was initially used for turbine engines, but has been used more recently for various other applications including refrigeration. The standard forward Brayton cycle is used to produce work or thrust for engine applications, while the reverse cycle is used for refrigeration and condensation applications.

The reverse cycle utilizes the basic thermodynamic principle of reducing the pressure of air to lower its temperature. Figure 1 shows an ideal regenerative reverse Brayton cycle. The solventladen effluent stream is first compressed isentropically (steps 1 to 2). Heat is then extracted from the stream at constant pressure in a regenerator (steps 2 to 3).

Because heat is extracted (rather than added) at this point, the process is called a reverse cycle. At step 3, the temperature of the gas stream is cold enough to condense about $80 \%$ to $90 \%$ of the solvent. More heat is extracted from the stream in the turbine (steps 3 to 4 ) to lower the temperature even further and condense the remaining solvent. The work produced by the turbine partially drives the compressor. To complete the cycle, the cold, solvent-free gas is passed through the other side of the regenerator to recoup heat at constant pressure.
The features of the reverse Brayton cycle that make it an attractive alternative technology for solvent recovery include

- Wide applicability

- Inherent stability

- High reliability

- High turndown ratio

- Ability to achieve condensing temperatures as low as $-150^{\circ} \mathrm{F}\left(-101^{\circ} \mathrm{C}\right)$.

In addition, the solvents recovered in the cycle are not contaminated during condensation and are readily reusable.

The optimum Brayton system design for a specific application depends on solvent properties such as boiling point, vapor pressure, flash point, and chemical structure. The recovery rates for solvents using the Brayton cycle depend on their condensing temperatures; the amount of solvent that is recoverable increases as the cycle temperature decreases. Table 1 gives some examples of solvents that the reverse Brayton-cycle system is capable of recovering. The condensing temperatures given are those required to reduce concentrations to approximately 1,000 parts per million (ppm) by volume.

The Brayton cycle can also be integrated with a carbon adsorption/inert gas process to regenerate the adsorbent bed. This approach provides a more economical implementation of inert gas regeneration by allowing lower temperatures as the inlet solvent concentration decreases in the 


\section{Table 1}

Examples of Fluids that

Can Be Condensed with the Brayton-Cycle Heat Pump

\begin{tabular}{lcc}
\hline Solvent & $\begin{array}{c}\text { Normal } \\
\text { boiling } \\
\text { point } \\
\left({ }^{\circ} \mathrm{F}\right)\end{array}$ & $\begin{array}{c}\text { Condensing } \\
\text { temperature } \\
\left({ }^{\circ} \mathrm{F}\right)\end{array}$ \\
\hline R-14 & -198 & -297 \\
R-22 & -41 & -190 \\
Methyl chloride & -11 & -174 \\
R-114 & 39 & -140 \\
R-11 & 75 & -120 \\
Methylene chloride & 105 & -94 \\
R-113 & 118 & -90 \\
THF & 151 & -66 \\
MEK & 175 & -55 \\
Toluene & 231 & -16 \\
1,1,1 Trichloroethane & 237 & -62 \\
MIBK & 246 & 30 \\
Perchloroethylene & 249 & -5 \\
DMF & 307 & 45 \\
DMSO & 372 & 32 \\
\hline
\end{tabular}

regeneration step. The outlet stream temperature from the turbine also decreases as the inlet solvent concentration decreases. The resulting decrease in solvent saturation temperature reduces the volume of the solvent being recycled, thus increasing the system's operational capacity between regenerations.

\section{DOE Project}

Solvent manufacturing processes consume a significant amount of energy. The recycling and reuse of solvents saves energy by reducing the use of energy-intensive incineration processes and by lowering the demand for new solvents. Solvent recovery technologies also contribute to OIT's goal of minimizing industrial wastes.

DOE has developed the Brayton-cycle solvent recovery heat pump technology in a series of $R \& D$ projects with AiResearch, 3M, and NUCON. Their efforts have resulted in the installation and operation of heat pump systems to recover solvents from effluent streams of 8,000 to 10,000 standard cubic feet per minute $(\mathrm{cfm})(3,775$ to $4,720 \mathrm{~L} / \mathrm{s})$ at three $3 \mathrm{M}$ manufacturing facilities. In two of the installations, activated carbon beds are regenerated with hot inert gas provided by Brayton-cycle systems. A mobile decoupled system, for use with small emitters, is also being demonstrated in California. The balance of this report summarizes $R \& D$ efforts and proof-of-concept industrial tests and reviews the potential impact of this technology on industry. 


\section{Project History and Status}

$I$ n $19773 \mathrm{M}$, as part of its efforts to comply with the Clean Air Act, teamed with AiResearch to develop and demonstrate a 2,000-cfm (944-L/s) experimental Brayton-cycle heat pump to condense solvent vapors emitted from a drying oven at a $3 \mathrm{M}$ facility in St. Paul, Minnesota. The demonstration was successful and drew the attention of DOE staff, who recognized that a full-scale system would need to be developed and tested before commercialization of this promising new technology could occur.

DOE began co-funding R\&D on the use of the reverse Brayton cycle to recover solvents in 1979. The initial effort consisted of a 6-year cooperative agreement with AiResearch to develop, design; and demonstrate an 8,000-cfm $(3,775-\mathrm{L} / \mathrm{s})$ Brayton-cycle solvent recovery heat pump. The $3 \mathrm{M}$ Company was selected as the demonstration host for the system because the company was a large solvent user and had extensive experience with various recovery methods. This cooperative effort was the beginning of a DOE program that was to extend over a period of more than 12 years and involve a wide variety of industrial, government, and institutional partners.

The DOE/AiResearch project was conducted in three phases. The first phase consisted of engineering and design activities, including the development of the turbine machinery for the reverse Brayton-cycle system. The cycle was analyzed and optimized for various solvent recovery applications using selected system designs. These analyses revealed the flexibility of the Brayton cycle and its potential for effective integration into a wide range of industrial processes. A high market penetration potential for Brayton-cycle recovery systems was also predicted.

During the second phase of the project, a prototype system was designed and fabricated to recover solvents at a $3 \mathrm{M}$ magnetic tape production facility in Hutchinson, Minnesota (Figure 2). The most important feature of this system was a newly designed electric-motor-driven turbocompressor that operated at 16,500 revolutions per minute

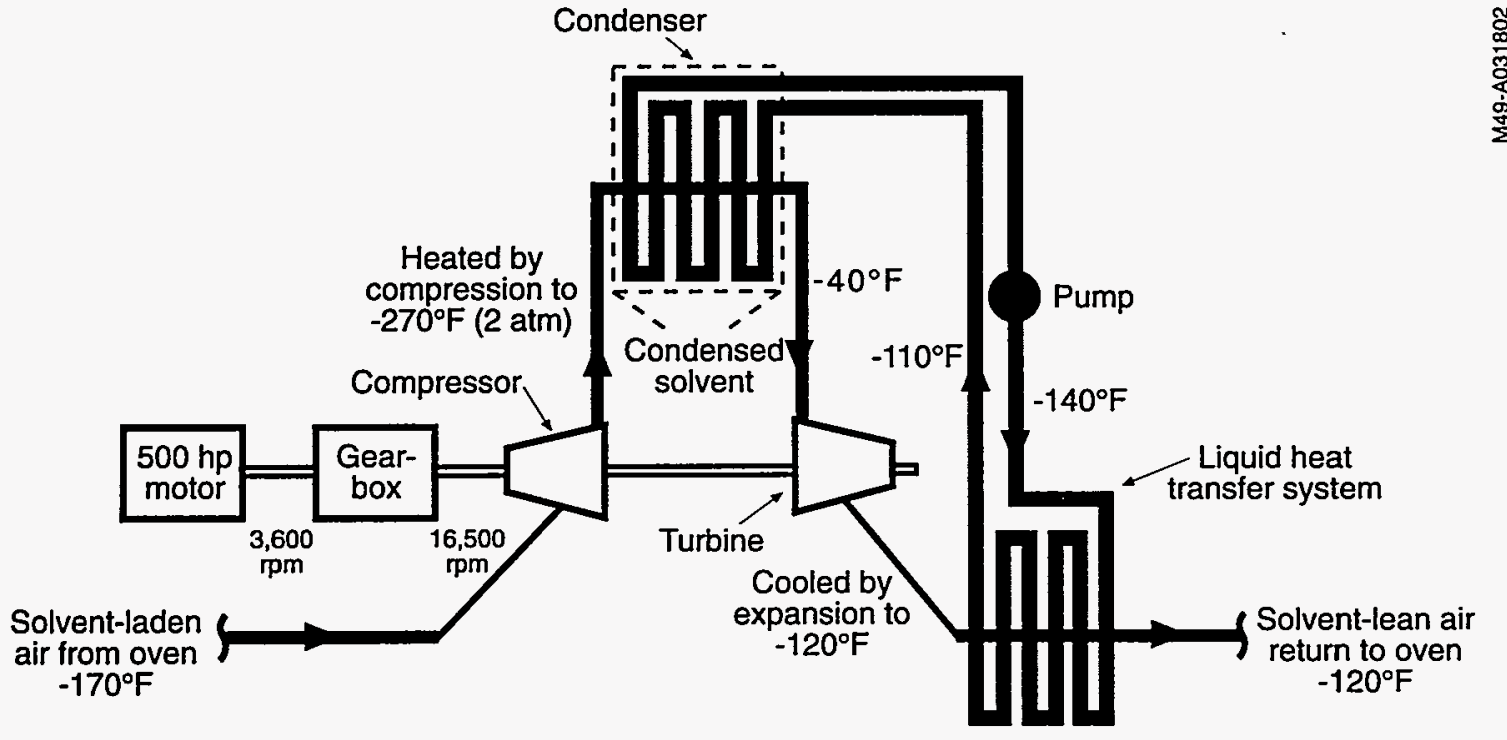

Figure 2. 3M Hutchinson Brayton system 
(rpm) through specially manufactured gearboxes driven by a 3,500-rpm motor.

The third and final phase of this project, which was completed in 1985, was the installation and demonstration of the prototype system at the $3 \mathrm{M}$ facility. The Hutchinson system was used for more than 200 hours of operation. The system was capable of removing 500 pounds $(227 \mathrm{~kg}$ ) of solvents per hour, equivalent to more than 3 million pounds (1.4 million $\mathrm{kg}$ ) of solvents per year under near full-time operation.

An assessment of the potential uses for the technology revealed that solvent condensation, even at the low temperatures possible with the Brayton cycle, could not achieve desired recovery efficiencies because of low inlet solvent concentrations. However, $3 \mathrm{M}$ also recognized that it would be possible to use the Brayton-cycle refrigeration process to condense solvents from a recirculating gas stream used to regenerate an adsorbent bed.

Both the straight condensation process and the adsorption/regeneration process were the subjects of patents awarded to the 3M Company during the mid-1980s.

To develop and demonstrate its new adsorption technology, 3M contracted with NUCON to perform laboratory tests of the concept using a 3-in. $(7.6-\mathrm{cm})$-diameter adsorber. Upon the successful completion of these tests, NUCON designed and fabricated an improved, transportable 250-cfm (118-L/s) pilot-system for testing at 3M's magnetic media facility in Camarillo, California. The mixture of methyl ethyl ketone (MEK), toluene, and cyclohexanone in the exhaust stream was effectively removed by the Brayton system.

A second-generation, full-scale industrial system (incorporating a carbon bed adsorption/inert gas regeneration system) was then designed, fabricated, and installed at 3M's Weatherford, Oklahoma, facility. The Weatherford solvent recov- ery system has been operating for over 5 years with an availability of over $98 \%$. The Weatherford system design differed substantially from the earlier Hutchinson system design:

- Activated carbon beds were used to adsorb and concentrate solvent from the effluent stream.

- The Brayton-cycle system was used to regenerate the carbon bed with inert nitrogen gas.

- A molecular sieve dryer was used as an intermediate step between the adsorption and regeneration of the carbon bed to remove water (and eliminate ice formation) from the solvent-laden gas stream.

- A free spindle compressor-expander was used in combination with a rotary blower to decouple the input shaft power to the system from the compressor/turbine. This eliminated the expensive, high-speed gearbox used in the Hutchinson system.

In mid-1987, DOE decided to intensify its efforts to demonstrate and publicize the technology to promote its acceptance by industry. In December 1987, DOEissued a solicitation for proposals for a three-phase project to design, fabricate, and test advanced heat pump technology for solvent recovery. There were two main goals for this project:

1. To demonstrate economic solvent recovery from large (1,000-tons/yr, 10,000-cfm [909-metric tons $/ \mathrm{yr}, 4,720-\mathrm{L} / \mathrm{s}]$ and greater) effluent streams. A payback of less than 3 years based on the total installed cost of the equipment and a solvent price of $\$ 0: 03 /$ pound $(\$ 0.66 / \mathrm{kg})$ (independent of environmental regulatory costs) was targeted.

2. To demonstrate a mobile recovery system for use with small (less than 500-tons/yr, 1,000-cfm [455-metric tons/yr, 472-L/s]) effluent streams. This system was to demonstrate annualized costs of less than $\$ 1,000 /$ ton $(\$ 1,100 /$ metric ton) for controlling various types of emission sources.

After evaluating the responses to this solicitation DOE awarded contracts for two systems, both of which are now in operation. DOE awarded contracts to $3 \mathrm{M}$ for the design and fabrication of a large Brayton-cycle system that was installed at 3M's Greenville, South Carolina, facility. The development of a recovery system for smallsource emitters is being performed under a DOE cooperative project with NUCON, 3M, Southern California Edison, EPRI, and Dow Chemical. The results of these projects will yield data that can be used to further evaluate the competitiveness of the system with alternative solvent-recovery systems, the quality of the recovered solvents, the capital and operating costs of the units, and the market potential of the Brayton-cycle heat pump technology. 
E fforts to develop Brayton-cycle solvent recovery technology over the past 15 years have resulted in the installation and operation of systems at two $3 \mathrm{M}$ manufacturing plants: the Hutchinson, Minnesota, magnetic media plant and the Weatherford, Oklahoma, magnetic media plant. In addition to these demonstration systems, an advanced system is being installed at 3M's Greenville, South Carolina, facility and a pilotscale mobile unit is being demonstrated in California as part of a cooperative effort between DOE, private industry, and the electric utility industry.

A brief description of each of these systems and the proof-of-concept tests performed are provided in this section.

\section{Hutchinson System}

Prior to installing the first prototype Brayton system at the Hutchinson facility, AiResearch conducted water-injection-only tests to prove that the system could operate for an extended time period with a substantial quantity of water vapor present. AiResearch also showed that the system had the capacity to provide sufficient refrigeration to condense the desired solvent/water mixtures. Solvent/water vapor tests were performed to develop the control settings for system operation, to monitor wear on critical system components, to assess overall system operation at minimum design conditions, to establish baseline runs for * comparison when the system was installed at the $3 \mathrm{M}$ facility, and to evaluate the freezing and/or hydrating of the heat exchangers operating in solvent mixtures with and without the presence of water. The results of two solvent/water tests are summarized in Table 2, and show condensable recovery efficiencies of $85 \%$ and $89 \%$.

The system installed at the Hutchinson facility was used to process an 8,000 -cfm $(3,775-\mathrm{L} / \mathrm{s})$ warm solvent/air stream emitted from a drying oven. This stream contained MEK, toluene, and cyclohexanone. The solvent-laden air stream, which was at approximately $45 \%$ of the lower
Table 2

\section{Selected Test Data Summary}

\begin{tabular}{|c|c|c|}
\hline Test number & 16 & 22 \\
\hline Run time (h) & 8 & 1.5 \\
\hline Remarks & $\begin{array}{c}60 \% \text { MEK } \\
40 \% \text { Toluene }\end{array}$ & $\begin{array}{c}\text { 63\% MEK } \\
13 \% \text { Toluene } \\
16 \% \text { Cyclohexanone } \\
8 \% \text { Xylene }\end{array}$ \\
\hline $\begin{array}{l}\text { Injection (lb) } \\
\text { Solvents } \\
\text { Water } \\
\text { MEK } \\
\text { Total }\end{array}$ & $\begin{array}{r}3,440 \\
103 \\
0 \\
3,543\end{array}$ & $\begin{array}{r}600 \\
18 \\
67 \\
685\end{array}$ \\
\hline Efficiency (\%) & 89 & 85 \\
\hline
\end{tabular}

explosion limit, was compressed by the Brayton cycle to a pressure of two atmospheres (atm). The heat of compression was removed with a condensing heat exchanger. This heat exchanger lowered the temperature to a point where the majority of the solvents would condense. The system also used a redundant condensing heat exchanger to defrost ice that collected during the condensing cycle. The air stream was further cooled by its expansion in the turbine to temperatures of less than $-120^{\circ} \mathrm{F}\left(-84^{\circ} \mathrm{C}\right)$. After this expansion, essentially all of the remaining solvents were condensed and removed. The warm, solvent-free air was then returned to the oven. Approximately $93 \%$ of the solvents contained in the air stream were effectively removed by the Brayton-cycle system.

\section{Weatherford System}

Like the Hutchinson system, the system at Weatherford was used to recover MEK, toluene, and cyclohexanone from a drying oven used in the production of magnetic media. The biggest difference between the two systems is that the Weatherford system was used in combination with a carbon adsorption process.

The overall Weatherford solvent recovery process is shown in Figure 3. The two carbon 

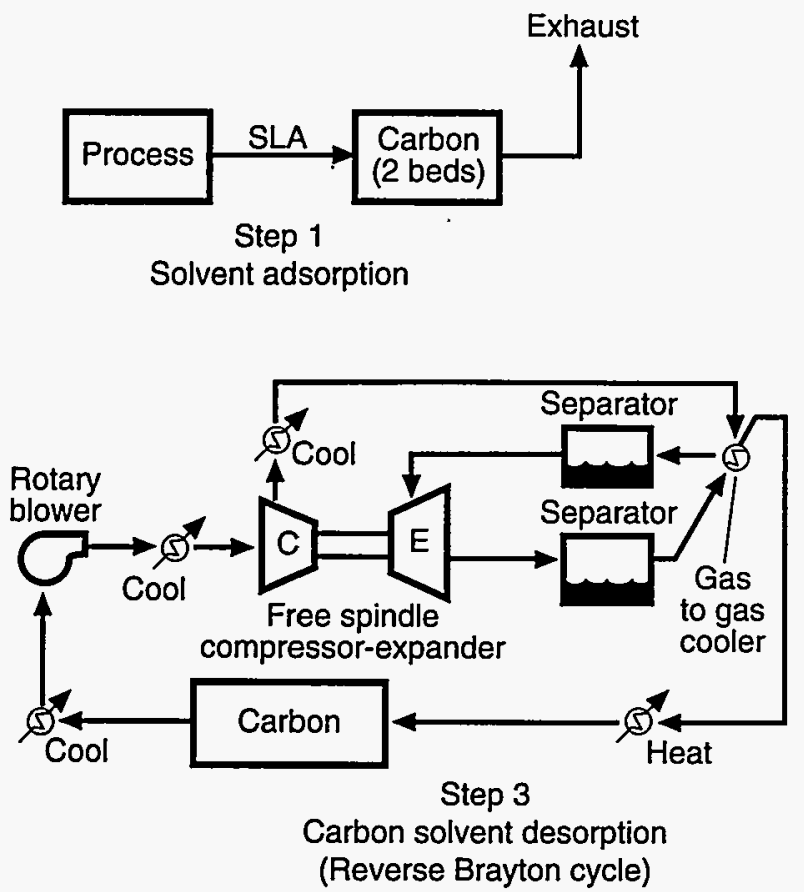

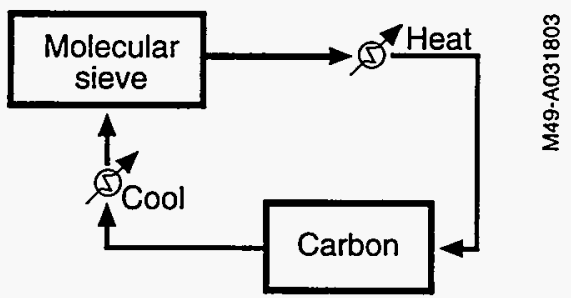

Step 2

Carbon dehydration

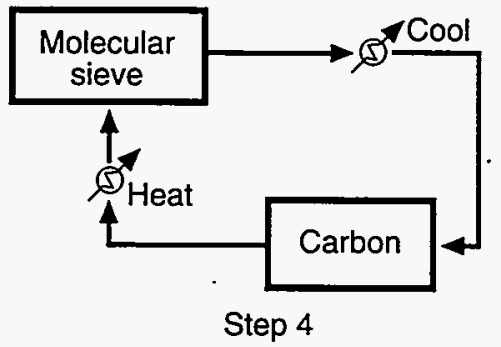

Molecular sieve regeneration

Figure 3. 3M Weatherford Brayton concentrator system

beds are cycled betwern step 1 and steps 2 and 4 . Therefore, while one bed is adsorbing solvents at step 1 , the other is being regenerated by step 2 (carbon dehydration), step 3 (carbon solvent desorption with the reverse Brayton cycle), and step 4 (molecular sieve regeneration). Solventladen, inert nitrogen gas from the carbon bed is compressed in the compressor side of the free spindle in the system and cooled by heat interchange with the expander. After this compression, the first portion of solvents is condensed and removed. The gas stream is then expanded in the turboexpander, where it is cooled to a temperature below $-70^{\circ} \mathrm{F}\left(-57^{\circ} \mathrm{C}\right)$. This facilitates the condensation recovery of the remainder of the solvents in the stream. The purified carrier gas is then reheated before reentry into the adsorber to perform further solvent stripping. When all of the solvents are removed from the carbon bed, the bed is cooled down, and the water adsorbed by the molecular sieve in step 2 is readsorbed onto the carbon bed.

The typical inlet solvent concentration is $3,000 \mathrm{ppm}$ with an air flow rate of about $8,000 \mathrm{cfm}$ $(3,775 \mathrm{~L} / \mathrm{s})$. Table 3 provides a summary of the system operation.

Table 3

Operational Data for Weatherford System

\begin{tabular}{lr} 
Air flow rate & $8,000 \mathrm{cfm} / \mathrm{bed}$ \\
Number of carbon beds & $3(2 \mathrm{in}$ use $)$ \\
Weight of carbon bed & $10,000 \mathrm{lb}$ \\
Adsorption cycle length & $12 \mathrm{~h}$ \\
Regeneration gas flow & $2,500 \mathrm{cfm}$ \\
Condensing temperature & $-70^{\circ} \mathrm{F}$ \\
Energy use & $2,000 \mathrm{Btu} / \mathrm{lb}$ solvent \\
\hline
\end{tabular}


- The unusually low 12-hour adsorption cycle is attributable to the higher working capacity of the activated carbon in the Brayton-cycle process. Because this was an early design of the technol-. ogy, the energy requirement of $2,000 \mathrm{Btu} / \mathrm{lb}$ ( 4.6 million joules $/ \mathrm{kg}$ ) of solvent is considered relatively high. However, this amount is still significantly lower than that required for carbon adsorption/steam regeneration systems.

The inlet and outlet solvent concentrations during a test cycle at the plant are shown in Figure 4 . The typical inlet concentration was about $1,600 \mathrm{ppm}$ by volume; the outlet concentration was 5 to $10 \mathrm{ppm}$ during most of the regeneration cycle. The adsorption cycle was terminated after 9 hours and the bed was regenerated. In general, the recovery efficiency of the Weatherford system is $98 \%$ and the recovered condensate contains less than $1 \%$ water.

\section{Greenville System}

An 8,000-cfm (3,775-L/s) advanced Braytoncycle system has been installed to contrul a 1,000-ton/yr (909-metric tons/yr) V(XC etflue'nt

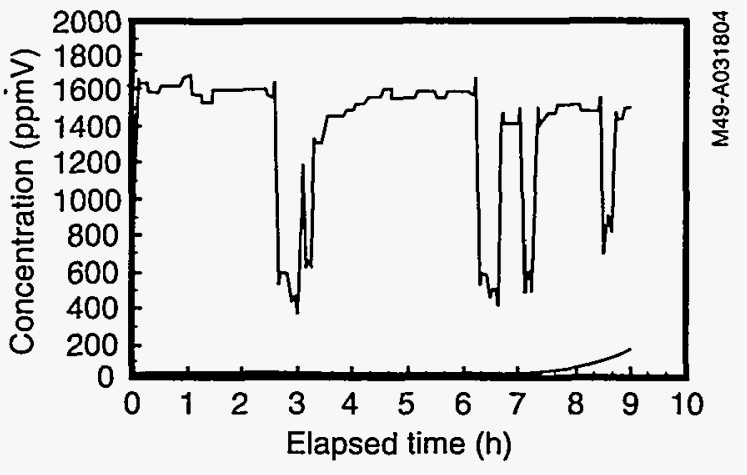

Figure 4. Inlet/outlet concentration-Weatherford

stream at 3M's Greenville, South Carolina, manufacturing plant. The effluent stream has a solvent concentration of approximately $2,000 \mathrm{ppm}$ and contains a mixture of heptane, xylene, toluene, and isopropyl alcohol. The Brayton system will be used to provide an inert nitrogen stream for alternately stripping solvent from one of two adsorbent beds. The system will then remove over $99 \%$ of the solvents from the nitrogen after it is returned from the adsorption bed (see Figure 5).

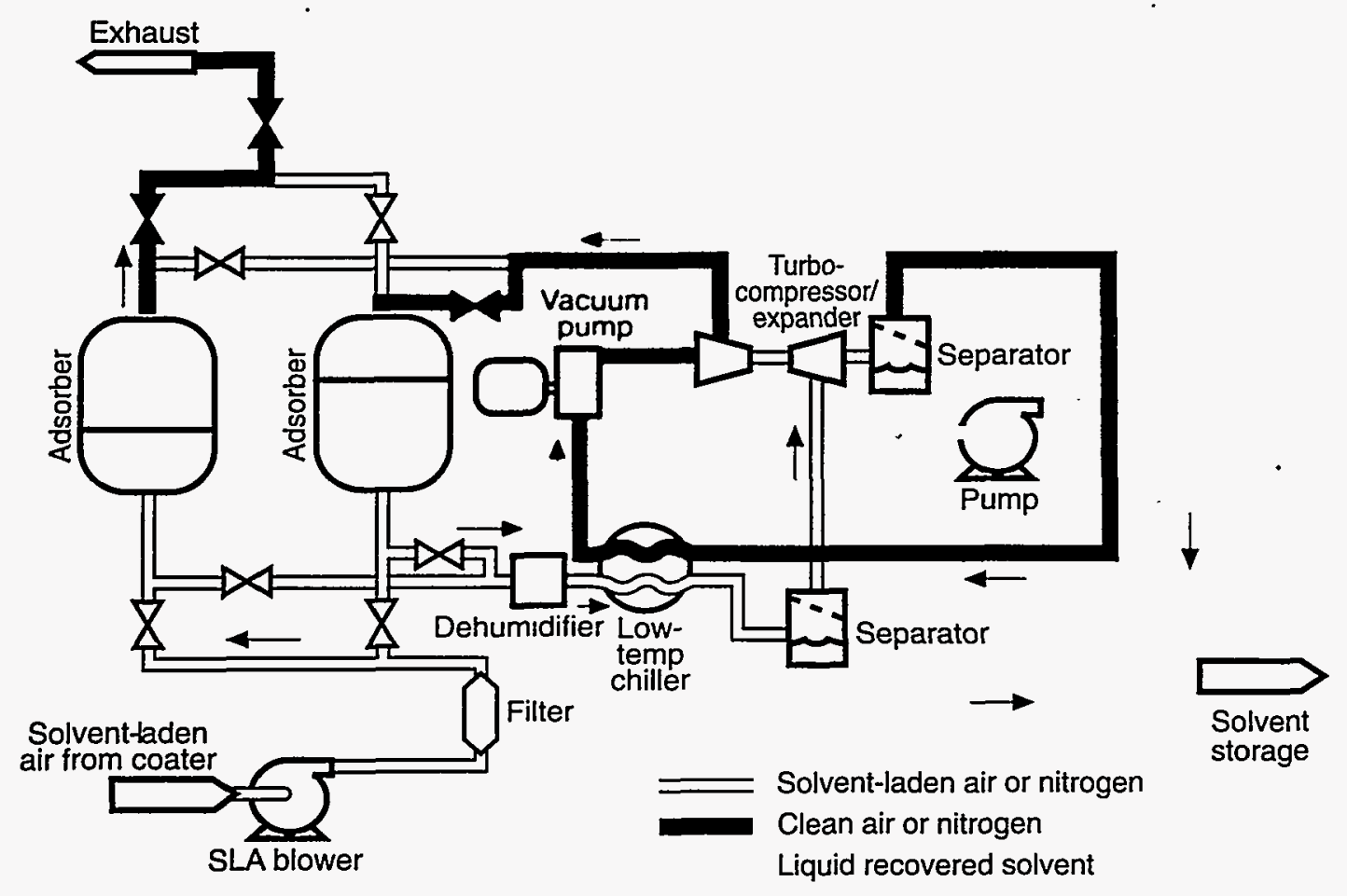

Figure 5. 3M Gteenville advanced Brayton-cycle sytem 


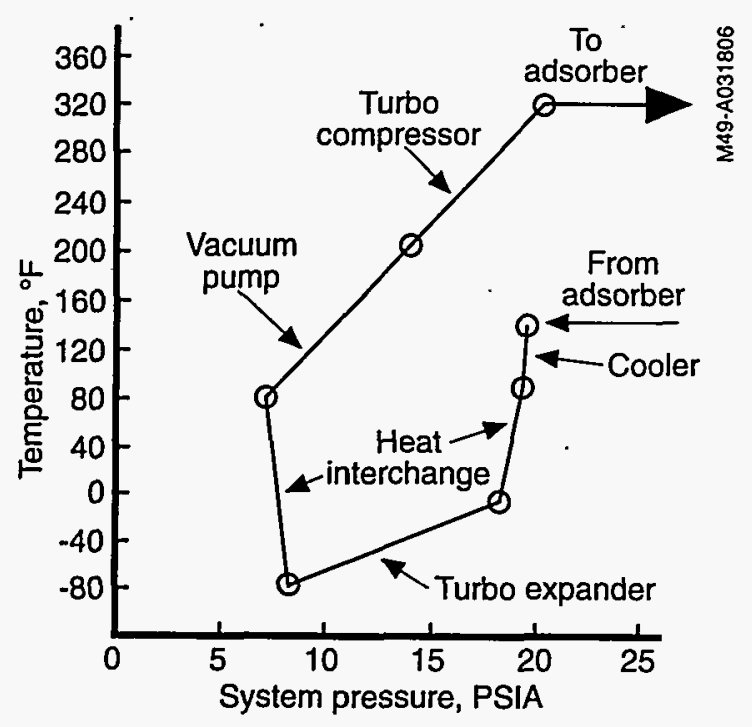

Figure 6. Temperature vs. pressure for BRAYSORB process

This process-officially known as BRAYSORBwas developed by NUCON under Phase I of its cosponsored project with DOE. A plot of temperature versus pressure for the BRAYSORB process is shown in Figure 6.

The Brayton cycle provides a high enough temperature $\left(320^{\circ} \mathrm{F}\left[160^{\circ} \mathrm{C}\right]\right)$ that no additional process heat is required to regenerate the adsorbent beds. The only energy input required is electricity to drive the Brayton system, eliminating the need for steam production or auxiliary heating systems. The equipment costs and energy consumption of the Greenville system are less than that for the
Weatherford system. This advanced system began operation in 1992.

Table 4 summarizes the progressive improvements in the performance of the Brayton-cycle heat pump systems installed at the three $3 \mathrm{M}$ facilities.

\section{Small Mobile Pilot-Plant System}

A mobile pilot solvent recovery unit, rated to handle a $250-\mathrm{cfm}(118-\mathrm{L} / \mathrm{s})$ solvent-laden air stream, was demonstrated at four host sites in southern California. This system was cosponsored by DOE, Southern California Edison, EPRI, NUCON, and $3 \mathrm{M}$.

The pilot-plant system was able to handle a wide range of solvents including perchloroethylene, methylene chloride, pentane, R-22, toluene, and heptane. The pilot plant provides the ability to quickly assess the efficacy of the Brayton-cycle . concept for a particular facility and to provide data required for a full-scale design. Operation of the pilot-plant system also provided valuable design data for the development of a new Braytoncycle system intended for use with smaller VOC emitters,

\section{Mobile Decoupled System}

The problem with small VOC emitters is the lack of capital resources necessary to install most VOC control systems. A typical solution is to use a carbon bed that is then sent off site for regeneration. This has the advantage of low initial capital cost, but results in high operating costs.

Table 4

Cost and Performance Improvements in 3M's Systems

\begin{tabular}{|c|c|c|c|}
\hline & Hutchinson & Weatherford & Greenville \\
\hline Stream size (cfm) & 8,000 & 8,000 & 8,000 \\
\hline When designed and built & $1979-1984$ & $1985-1987$ & $1988-1991$ \\
\hline Solvent type & $\begin{array}{l}\text { MEK, toluene, } \\
\text { cyclohexanone }\end{array}$ & $\begin{array}{l}\text { MEK, toluene, } \\
\text { cyclohexanone }\end{array}$ & $\begin{array}{l}\text { Heptane, xylene, } \\
\text { isopropyl alcohol, } \\
\text { toluene }\end{array}$ \\
\hline $\begin{array}{l}\text { Concentration (ppm) } \\
\text { Power required (hp) } \\
\text { Equipment cost }\end{array}$ & $\begin{array}{l}4,000 \\
550 \\
\$ 1,500,000^{*}\end{array}$ & $\begin{array}{l}2,000 \\
450 \\
\$ 1,000,000^{*}\end{array}$ & $\begin{array}{l}2,000 \\
180 \\
\$ 950,000^{*}\end{array}$ \\
\hline
\end{tabular}

" Estimated equipment costs in 1990 dollars to replicate the installed equipment.

This does not include installation cost.

Source: Nirmal Jain, “Solvent Recovery Using the Brayton Cycle Heat Pump,". August 1990. 
Table 5

Decoupled Host Site Summary

\begin{tabular}{llrr}
\hline & \multicolumn{1}{c}{ Solvent } & \multicolumn{2}{c}{ Solvent-laden air } \\
\cline { 3 - 4 } Host site & \multicolumn{1}{c}{ Flow rate } & Concentration \\
\hline Bandag Tire & $1,1,1$ Trichloroethane & $3,500 \mathrm{scfm}$ & $400 \mathrm{ppm}$ \\
Hughes Missile Systems & $1,1,1$ Trichloroethane & $500 \mathrm{scfm}$ & $50-100 \mathrm{ppm}$ \\
Optical Radiation & Methylene chloride & $2,000 \mathrm{scfm}$ & $100-200 \mathrm{ppm}$ \\
Barcel & $1,1,1$ Trichloroethane, NMP & $3,000 \mathrm{scfm}$ & $5-50 \mathrm{ppm}$ \\
Chevron & Gasoline & (a) & (a)
\end{tabular}

(a) Chevron has not yet started soil remediation. so solvent-laden air flow rate and concentration are not known.

To address this problem, a project cosponsored by DOE, Southern California Edison, South Coast Air Quality Management District, and NL'C(N) was initiated to develop a decoupled Bravton-cicle system, in which carbon adsorbent beds are lixiated at each of several sites. A single trailer-mounted heat pump, owned by a service compans trasels from site to site, regenerating the beds on a periodic basis as they become loaded with VOCs. In this way, each individual facility pays a fee for each regeneration, rather than buying a regenerator. Table 5 presents a summary of the five host sites participating in the demonstration of the decoupled system. 


\section{Applications}

$T$ he Brayton-cycle heat pump system can be used in solvent recovery applications throughout industry - to recover solvents used as fuel components, as refrigerants, in plastics and plastic foam manufacturing, in hydrocarbon production and distribution, and in textile manufacturing. The system can also be used to recover various types of solvents from industrial coating and cleaning operations such as painting and magnetic media manufacture. The wide range of applicability of the technology allows the recovery of valuable solvents in an energy-efficient manner, as well as the reduction of VOC emissions from many types of industrial processes.
The reverse Brayton cycle can be used in the following four different configurations.

\section{Indirect Condensation}

The indirect condensation mode is suitable when the solvent concentration is so high that there is insufficient noncondensable gas to drive the turboexpander. The flow diagram for this process is illustrated in Figure 7. The condensation loop is not in direct contact with the solvent-laden stream. This closed-cycle system, using any gas with optimized heat capacity, can be operated in remote locations using diesel engine-driven

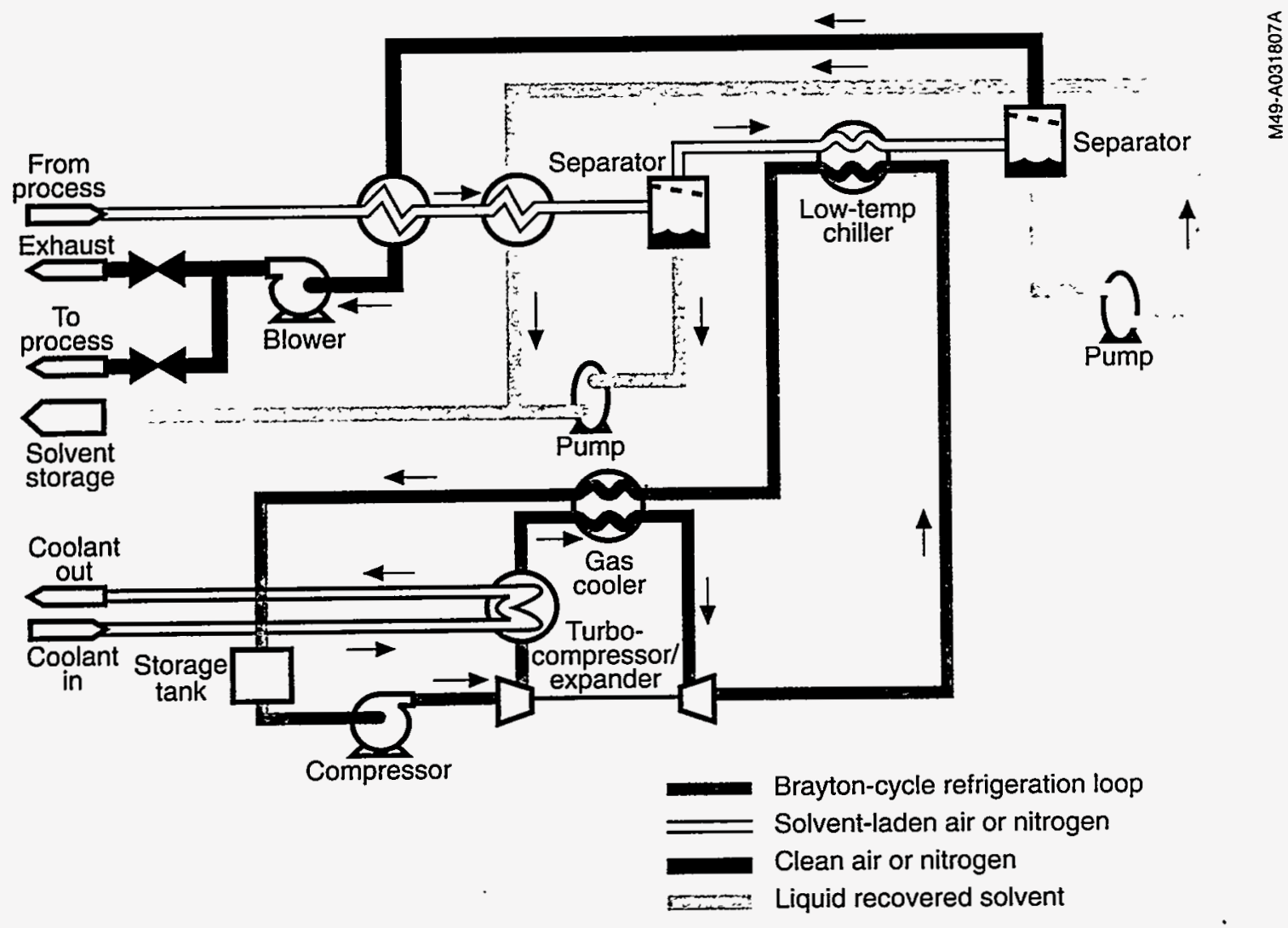

Figure 7. Indirect condensation 
compressors or turbopackages. NUCON is currently designing an indirect condensation system for recovering gasoline vapors at storage tanks, refineries, or tanker truck terminals.

\section{Direct Condensation}

The direct condensation mode is used with streams containing solvent concentrations of $1 \%$ to $20 \%$ by volume. Figure 8 shows the flow diagram for the process. First, the solvent stream is dehumidified (if needed) and pre-cooled by the gas stream exiting from the solvent separator of. the turboexpander. Any solvents condensed at this point are removed in a gas/liquid separator. More solvents are condensed when the gas stream enters the turboexpander, where the temperature of the stream is further reduced to around $-100^{\circ} \mathrm{F}$ $\left(-73^{\circ} \mathrm{C}\right)$. Clean, solvent-free gas is then returned to the process after absorbing the heat generated by the turbocompressor. Lower condensing temperatures can be achieved by raising the pressure of the solvent-laden stream by passing it through the turbocompressor. The stream is then cooled in a water-cooled heat exchanger and sent to $a$. low-temperature, gas-to-gas heat exchanger. This type of arrangement can result in final solvent condensing temperatures as low as $-150^{\circ} \mathrm{F}\left(-101^{\circ} \mathrm{C}\right)$.

\section{Concentrator/Direct Condensation Regeneration-Coupled}

Direct condensation of solvents is not energy efficient when the solvent concentration is less than $1 \%$ by volume. In this case, a concentrator is used to increase the concentration of the solvent in the air stream for condensation in a Brayton-cycle system. The adsorbent beds are regenerated using the directly coupled system (see Figure 9). This regeneration process strips the solvents from the adsorber with a hot gas, condenses the solvent vapors in the resulting solvent-laden stream using the Brayton cycle, and returns essentially solventfree inert gas to the adsorber for further regeneration. No external heat source is typically needed; the compression heat generated is sufficient for stripping solvents from the adsorbent. Condensation temperatures of $-80^{\circ} \mathrm{F}\left(-62^{\circ} \mathrm{C}\right)$ are usually adequate for complete condensation of typical industrial solvents.

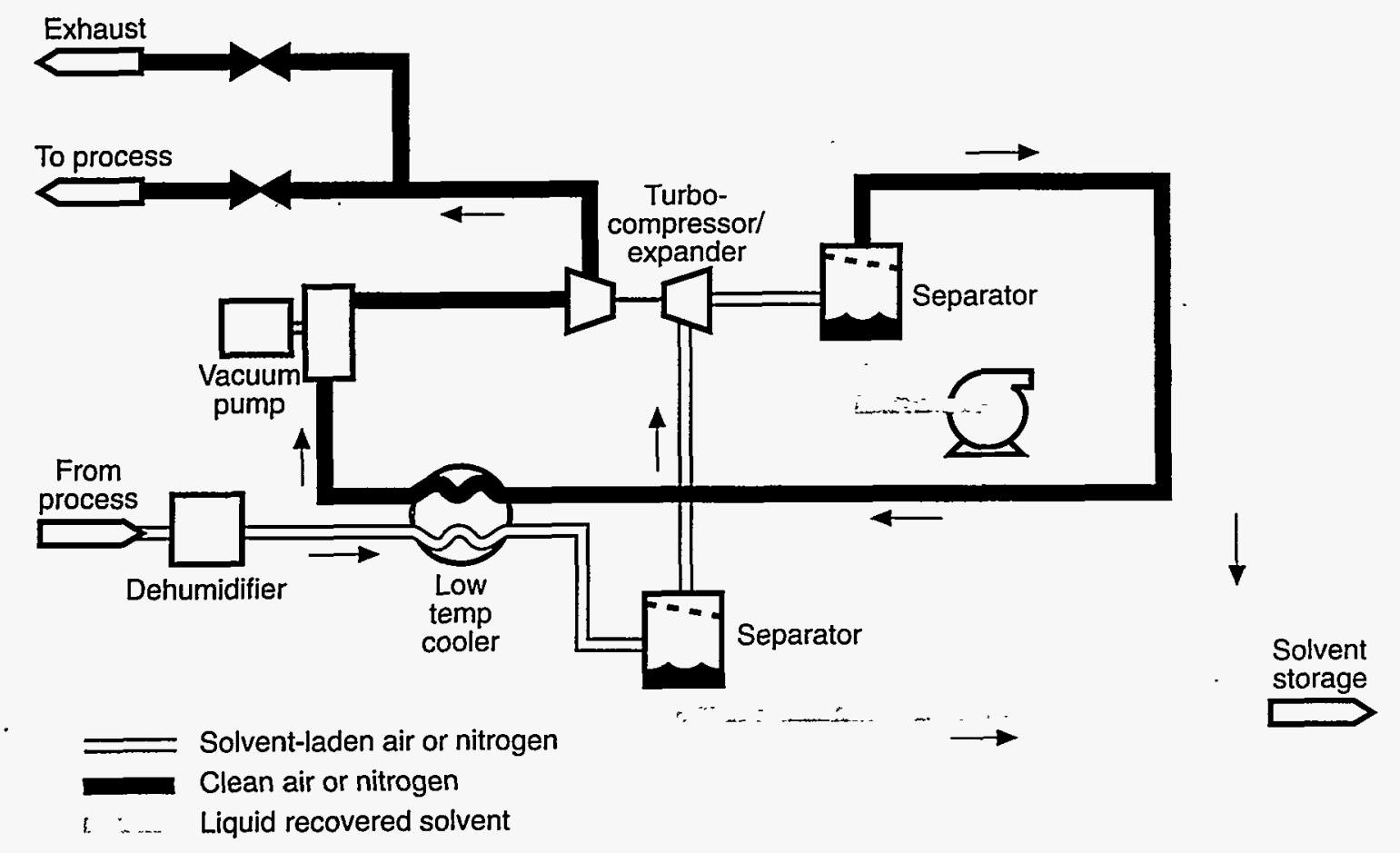

Figure 8. Direct condensation 


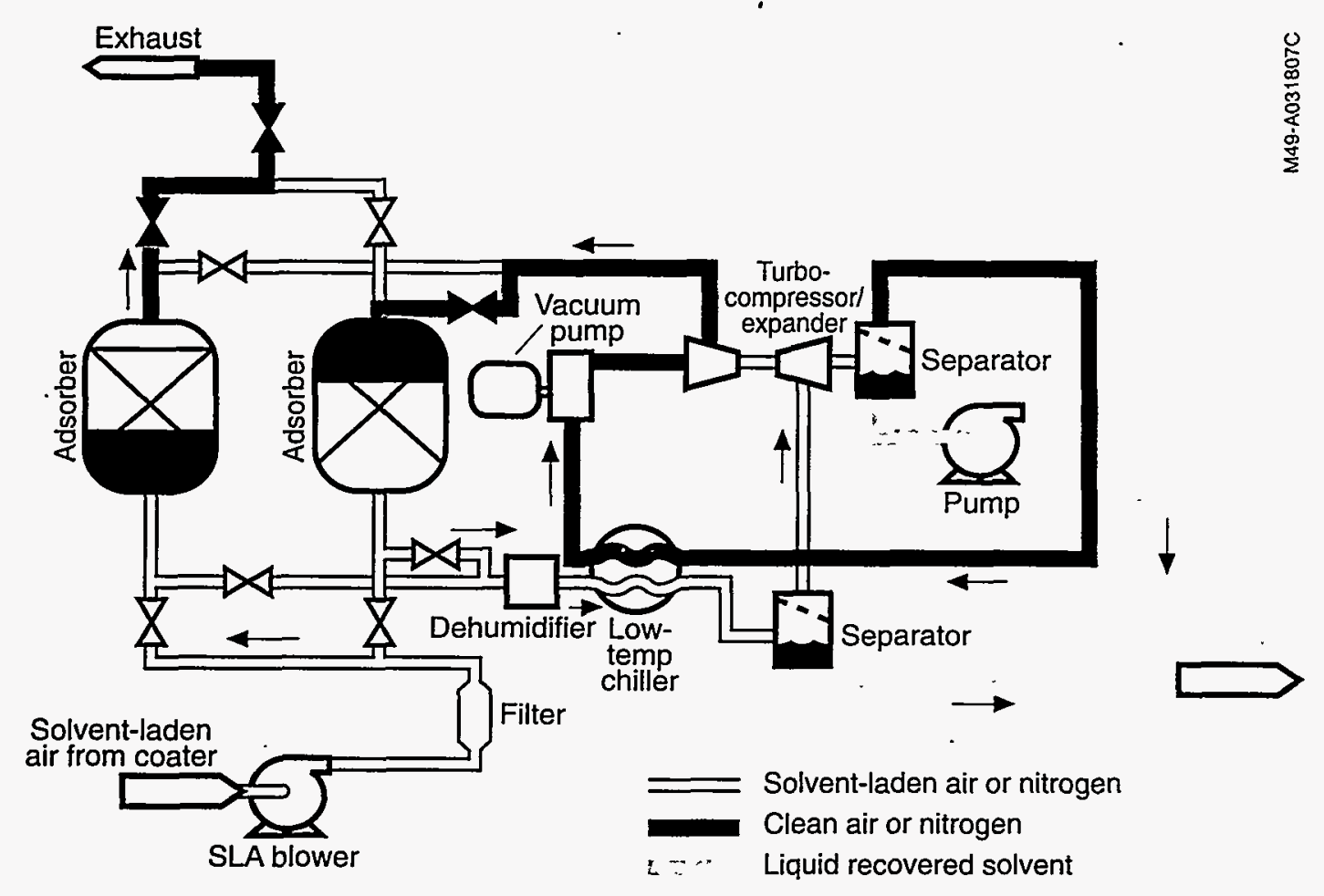

L

Figure 9. Concentrator/direct condensation regeneration-coupled

\section{Concentrator/Direct Condensation Regeneration-Decoupled}

The application of the technology in this mode permits economical pollution control and solvent recovery at locations releasing small volumes of solvents at very low concentrations. The regeneration system is physically separated from the adsorbers. Only the concentrators are located on site, and regeneration is performed in one of two ways.

In one system, the adsorber unit can be moved from the site to a conveniently located, central regenerator system. The other version of the decoupled approach is the use of a mobile regenerator that is transported between locations for regenerating carbon beds and recovering solvents (see Figure 10). In this way, the Brayton-cycle regeneration system can serve many adsorbers at different industrial sites. Typical regeneration frequencies range from once a day to once a month. This approach is also suitable for single plants with numerous small sources dispersed within the facility (e.g., large tank farms).

Brayton-cycle systems enable the condensation recovery of approximately $99.9 \%$ of solvents in an industrial effluent stream. Condensation temperatures as low as $-150^{\circ} \mathrm{F}\left(-101^{\circ} \mathrm{C}\right)$ can be achieved with a single compression stage. The Brayton process is capable of returning clean, hot gas for process utilization or as regeneration energy for solvent desorption processes. No wastewater streams are generated in the cycle, and the dry air regenerated from adsorber beds is also suitable for recycling.

The technology involves an energy-efficient solvent control technique that provides high-quality recovered solvents. The Brayton cycle is an established technology that has been used for decades in automobile turbochargers and in commercial and military jet aircraft to maintain cabin pressure and temperature. Its performance and reliability are thus well documented.

\section{Energy Potential}

The energy costs of operating an advanced Brayton-cycle heat pump design are very low compared to the energy costs of competing solvent recovery technologies. Table 6 provides an estimate of the energy use and costs for several 


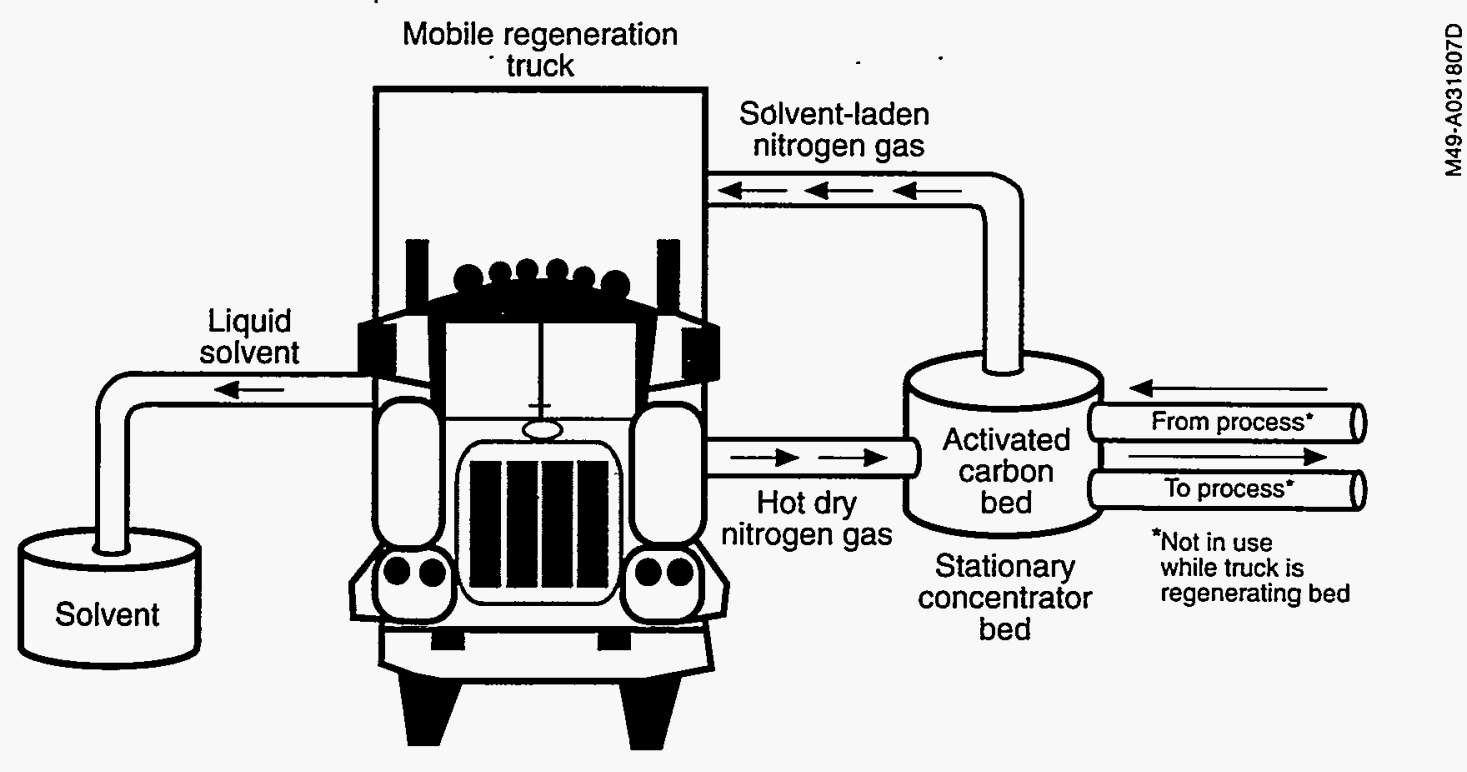

Figure 10. Concentrator/direct condensation regeneration—decoupled

state-of-the-art solvent recovery technologies, the existing Brayton-cycle installations, and the advanced system. Although the energy efficiency of the system is important, it will most likely have a minor role in determining economic viability in many applications. In most solvent recovery situations, energy costs represent less than $10 \%$ of the value of the recycled solvent. A controlling factor to the economics of most solvent recovery systems is the recyclability of the solvents; higher recyclability means less money spent on purchasing new solvents and a possible reduction in emission fees.

Table 6

Energy Use Comparison of Solvent Recovery Systems/Lb of Solvent

\begin{tabular}{|c|c|c|}
\hline & Energy use & Energy $\operatorname{cost}^{(a)}$ \\
\hline $\begin{array}{l}\text { Carbon bed/steam desorption } \\
\text { (with distillation) }\end{array}$ & 7,000 to $12,000 \mathrm{Btu}^{(b)}$ & $\$ 0.010$ to $\$ 0.050$ \\
\hline $\begin{array}{l}\text { Carbon bed/desorption } \\
\text { (without distillation) }\end{array}$ & 3,000 to $5,000 \mathrm{Btu}^{(b)}$ & $\$ 0.006$ to $\$ 0.020$ \\
\hline Incineration & 400 to $60,000 \mathrm{Btu}^{(b)}$ & $\$ 0.001$ to $\$ 0.30$ \\
\hline Hutchinson system & $\begin{array}{l}2,400 \mathrm{Btu}^{(\mathrm{c})} \\
0.068 \mathrm{kWh}\end{array}$ & $\$ 0.027$ \\
\hline Weatherford system & $\begin{array}{l}2,000 \mathrm{Btu}^{(\mathrm{c})} \\
0.59 \mathrm{kWh}\end{array}$ & $\$ 0.023$ \\
\hline Greenville system & $\begin{array}{l}500 \text { to } 1,000 \mathrm{Btu}^{(c)} \\
0.15 \text { to } 0.30 \mathrm{kWh}\end{array}$ & $\$ 0.005$ to $\$ 0.012$ \\
\hline
\end{tabular}

(a) Cost of thermal energy of $\$ 2$ and $\$ 5$ per million BTU assumed. Electrical energy of $\$ 0.04$ per $\mathrm{kWh}$ assumed.

(b) Thermal energy used in process.

(c) Mechanical shaft power input to process with electric motor drive.

Source: U.S. Department of Energy, "Brayton Cycle Solvent Heat Pump Project Status Report," February 1990. 




Figure 11. Annual operating cost versus value of recovered solvent

\section{Economic Potential}

Several companies are working with DOE to improve the economics of the Brayton-cycle systems. The main accomplishments over the last 15 years have been to reduce the technology's capital cost, reduce its energy consumption, and improve its reliability. The economic competitiveness of the technology depends not only on the capital and operating costs of the system, but also on the amount and the value of solvent recovered. Figure 11 shows the relationship between the net annual operating cost per pound of recovered solvent and the value of the solvent recovered for a range of solvent recovery rates. The basis for this plot is given in Table 7. As the value of the solvent increases or the amount of solvent recovered increases, the annual operating cost decreases. Eventually the cost becomes negative, implying that there will be positive payback for the system. The operating point for the $3 \mathrm{M}$ Greenville

\section{Table 7 \\ Basis for Economic Analysis}

Capital cost

Equipment cost

$\$ 970,000$

Installation cost

480,000

Total capital cost

Annual operating cost

Depreciation @ 5 years

Energy-170kW @ \$0.04/kWh

Nitrogen

Labor

Maintenance

Total annual operating cost system is shown as an annual operating cost of $\$ 0.18 / \mathrm{lb}(\$ 0.40 / \mathrm{kg})$ of solvent with a solvent value of $\$ 0.21 / \mathrm{lb}(\$ 0.46 / \mathrm{kg})$.

Comparing the Brayton-cycle system with other VOC control technologies, such as incineration or adsorption with steam regeneration, is difficult, because each is dependent on the nature of the VOC-laden air stream. No single technology will be correct for all conditions. Each will be most cost effective for a particular VOC type, concentration, flow rate, and value. Further cost reductions for the Brayton-cycle system are expected in the future as continued R\&D leads to design and operation enhancements. It also has the potential to yield payback periods within the 2- to 3-year time frame that industry will generally accept.

Based on an analysis for the use of a Braytoncycle system to recover eight widely used solvents (isopropyl alcohol, methyl chloroform, MEK, methylene chloride, perchloroethylene, toluene, trichloroethylene, and trichlorofluoromethane), the ranges of maximum potential savings for the new process are estimated at 10 trillion to 110 trillion Btu/yr, based on solvent quantity; $\$ 225$ million to $\$ 1.5$ billion/yr, based on product value; and $\$ 30$ million to $\$ 330$ million/yr, based on the energy value of the solvents.

These potential savings do not reflect the primary energy savings that would result from reduced solvent production. Also, this analysis was based on the recovery of only eight solvents, and thus does not cover all potential applications of the Brayton-cycle technology. Therefore, actual savings could be much higher than estimated.

\section{Future Work}

DOE envisions the Brayton-cycle technology as a method for reducing the energy consumption of VOC control technologies and for promoting solvent recycling through the use of more costeffective techniques that are suitable for both large and small solvent users. This will result in reduced demand for energy-intensive solvent production processes on a nationwide basis.

Future efforts are planned to continue improving the economics of solvent recovery using . Brayton-cycle heat pump technology and to continue demonstrating the energy conservation benefits of these systems. In order to assist small and medium-sized industrial companies, DOE is cosponsoring a project with Southern California Edison, NUCON, and Dow Chemical to develop and demonstrate a decoupled Brayton solvent 
recovery unit. Using the decoupled approach, solvent adsorbent beds located at different industrial sites can be regenerated on a weekly basis by bringing the Brayton solvent recovery system to the sites.

With,this technique, the solvent user would only have to purchase or lease an adsorption bed, significantly reducing the required investment.
A service fee would then be charged for regenerating the adsorption bed. The demonstration of a 1,500-cfm (708- $\mathrm{L} / \mathrm{s})$ mobile unit in the Los Angeles area was completed in May 1993. This affordable pollution control technology could conceivably recover a significant portion of the VOCs generated in southern California. 


\section{For More Information}

F or additional information on the Braytoncycle solvent recovery heat pump technology described in this document, consult the following publications:

"Brayton-Cycle Solvent Recovery Heat Pump Chemical Recovery Study," Prepared for the U.S. DOE Office of Industrial Technologies by RCG/Hagler-Bailly, Inc., August 31, 1990.

"Brayton-Cycle Solvent Recovery System Development Test Results," Prepared for the U.S. DOE by AiResearch Manufacturing Co., DOE/CS/40005, September 30, 1986.

"Brayton-Cycle Solvent Recovery System, Phase I, System Optimization," Prepared for the U.S. DOE by AiResearch Manufacturing Co., June 16, 1980.

"Brayton-Cycle Solvent Recovery System, Phase II, System Design," Prepared for the U.S. DOE by AiResearch Manufacturing Co., November 23, 1982.

Enneking, Joseph C., "The Brayton-Cycle Heat Pump for Solvent Recovery and Pollution Control," Presented at the U.S. DOE Industrial Solvent Recycling Conference, San Diego, CA, May 22, 1991.

Jain, Nirmal and Scheihing, Paul E., "Solvent Recovery Using the Brayton-Cycle Heat Pump," Proceedings of the AIChE Annual Meeting, August 1990.

Kovach, J.L., "Utilization of the Brayton-Cycle Heat Pump for Solvent Recovery," Presented at the U.S. DOE Industrial Solvent Recovery Recycling Conference, Charlotte, NC, October 15, 1990.

"The U.S. Department of Energy Brayton-cycle Solvent Recovery Heat Pump Project," Status Report, February 1990.
For information on the continuing development of the Brayton-cycle solvent recovery heat pump, contact:

Dr. Steve Priebe

Principal Program Specialist

Idaho National Engineering Laboratory

P.O. Box 1625

Idaho Falls, ID 83415-3875

(208) 526-0898

Mr. Paul E. Scheihing

Program.Manager

Office of Industrial Technologies, EE-221

U.S. Department of Energy

1000 Independence Avenue, SW

Washington, DC 20585

(202) 586-7234

Mr. Joseph C. Enneking

Vice President

NUCON International, Inc. (NUCON)

P.O. Box 29151

7000 Huntley Road

Columbus, $\mathrm{OH} 43229$

(614) $846-5710$ 